\title{
Decision to incision interval for emergency caesarean section and postoperative outcomes in a resource limited rural Kenyan public hospital
}

\author{
David Kamotho $^{1}$, Anne M. Pertet ${ }^{2 *}$, Isaac Ogwayo ${ }^{3}$
}

\author{
${ }^{1}$ Department of Nursing, Ministry of Health, Kenya \\ ${ }^{2}$ Department of Community Health, Tropical Institute of Community Health and Development, Kenya \\ ${ }^{3}$ Department of Nutrition, Great Lakes University of Kisumu, Nairobi, Kenya
}

Received: 10 May 2018

Accepted: 02 June 2018

\section{*Correspondence:}

Dr. Anne M. Pertet,

E-mail: apertet@gmail.com

Copyright: ( ) the author(s), publisher and licensee Medip Academy. This is an open-access article distributed under the terms of the Creative Commons Attribution Non-Commercial License, which permits unrestricted non-commercial use, distribution, and reproduction in any medium, provided the original work is properly cited.

\section{ABSTRACT}

Background: Standard guidelines recommend that delivery by caesarean section should be ideally initiated within 30 minutes of the decision to operate to avoid maternal and foetal compromise in labour. The purpose of this study was to investigate the extent to which these guidelines can be achieved in limited resource hospital.

Methods: Authors used a secondary data from 330 patient's files of women who had a caesarean section from December 2013 retrospectively to January 2012.

Results: The main indications for caesarean section was obstructed labour (18.5\%) for mothers and foetal distress (6.4\%). Though $74 \%$ of the mothers gave consent to be operated within the 30 -minute guideline, only $3 \%$ were prepared for operation within this period. Only $24 \%$ of the caesarean sections were conducted within one hour after the decision was made for the operation. About $38 \%$ of the women, and $30 \%$ of the babies developed complications after the caesarean section. Haemorrhage was the leading complication in mothers while the main complication for babies was babies with an Apgar score of 5 and below.

Conclusions: The 30- minute recommended guideline for caesarean section was not achieved, and there was evidence of adverse post-operative outcome as a result of not meeting the global standards.

Keywords: Caesarean section, Foetal compromises, Maternal compromise, Resource-limited hospital, Standard guidelines

\section{INTRODUCTION}

Caesarean section has a considerable potential to reduce maternal and perinatal deaths when there is an urgent threat to the health or life of the mother or baby. ${ }^{1}$ Grade 1 caesarean sections are performed when there is an immediate threat to the life of the mother and foetus. Grade 2 is performed when there is evidence of maternal or foetal compromise which is not immediately lifethreatening, grade 3 is performed when there is no maternal or foetal concern, but early delivery is required, while Grade 4 caesareans are the elective cases. ${ }^{2}$ Before caesarean section is performed, an informed decision is required from the patient or significant other after they are fully explained of the risks and benefits which requires sufficient time. A caesarean section also involves several preparatory procedures by the health staff which also requires additional time. ${ }^{3}$ Thus, while the time taken to consent is patient related, the preparatory procedures are health facility related. Both can add to delay in achieving delivery of the baby which has been postulated to cause clinical outcomes that could be harmful to either 
mother or baby or both. The Royal College of Obstetricians and Gynaecologists and Royal College of Anaesthetists stipulates that once a decision to operate has been made, delivery should be carried out with an urgency. They further note that while a target Decision to Delivery Interval (DDI) of 30 minutes is recommended where there is a foetal compromise, certain clinical situations will require a much quicker DDI than the 30 minutes. They further pointed out that undue haste to achieve a short DDI could also introduce its own risk, both surgical and anaesthetic, with the potential for maternal and neonatal harm. ${ }^{4}$ A hospital providing obstetric care should have the capability of responding to an obstetric emergency within the recommended time. However, in the developing nations, caesarean sections might take time to be initiated, as the skills and resources needed may not be adequate, which means that the risks associated with caesarean section could be much higher in the developing nations than in the developed nations.

Caesareans delivery has been reported to be achieved within 30 minutes if there are adequate qualified midwives to allow one-to-one care during active labour. ${ }^{2}$ Delays could be compounded by the fact that patients in developing countries may take time to be convinced or have to consult the family causing more delays. ${ }^{5}$ These conditions serve to underscore realities of the 30-minute dictum - of beginning a caesarean within 30 minutes of the decision to operate in a developing country.

Most studies to assess the adherence to the 30-minute dictum have been carried out in the developed world with a few conducted in the developing countries. Studies carried out in the past ten years indicate that more caesarean emergency operations were commenced within 30 minutes' guidelines in developed than in developing countries. From a systematic review out of 34 studies, only $36 \%$ of urgent emergency cases deliveries were achieved within 30 minutes. In the 13 studies that included neonatal outcomes, there was a higher risk of overall 5-minute Apgar score less than four. ${ }^{6}$ Details of these studies indicate that in the United Kingdom and the United States had adherence of between $55 \%$ to $65 \% .^{2,7}$ On the other hand, studies conducted in Africa show much lower adherence levels, ranging from one to six percent. ${ }^{8-11}$

Studies done in Kenyan public hospitals based in urban settings show an adherence rate of 0 to $3.8 \%$, with private hospitals reporting slightly higher achievements ranging from $8.6 \%$ to $20.4 \% .^{12,13}$ The purpose of present study was therefore to establish the extent to which these guidelines can be achieved in a rural resource-limited hospital.

\section{METHODS}

The study site was Garissa Level Five Hospital based in North Eastern Kenya, which serves also serves as a referral centre for refugees and patients from neighbouring countries of Somalia, Ethiopia, and Sudan. The hospital's catchment area is estimated to have a total population of 224,985 people. ${ }^{14}$ The ratio of midwives to patients is 1:7. The rate of caesarean section in the hospital is $18 \%$, which is much higher than the recommended World Health Organization rate of between 10 to 15 percent. ${ }^{15}$ Reported maternal outcomes associated with caesarean section were 11 maternal deaths, six cases of ruptured uterus, ten sepsis and 109 cases of post-partum haemorrhage. ${ }^{14}$

The study population comprised of women who delivered through an emergency caesarean section in the hospital retrospectively from December 2013 to January 2012. The sample size was determined using the Fisher et al, formula and adjusted for a population of less than 10,000. A p of 0.5 was used giving a sample size of 384 deliveries. The first case selected was the last woman to be delivered in December 2013. Other records of women who had delivered through caesarean section were picked retrospectively from that point until the required sample size was achieved, which took authors to January 2012.

\section{Study design and data collection}

Authors used a document review method secondary data from the maternity department. A data collection form was devised to extract information from the patient's files stored in the archives starting from December 2013 retrospectively. Decision to Incision Interval was calculated from the time the decision was made. This included the time taken to give consent, plus the time taken by the health workers to prepare the mother for the operation to the time the mother was given first dose of anaesthesia. Post-operative outcomes were the maternal and neonatal complications after delivery which included haemorrhage, sepsis, prolonged or obstructed labour, rupture of uterus in case of the mother and asphyxia, admission to the neonatal intensive care unit for up to 4 days, birth trauma, neonatal encephalopathy stage 3, seizures and low APGAR score of less than 4 in 5 minutes etc.

Maternal deaths were assessed as the death occurring after the operation as recorded in the patients file and not maternal mortality within 42 days of termination of pregnancy as this data was not available. Neonatal deaths were deaths of a new-born infant baby that occurred during delivery as recorded in the patients' file. The reliability of the data was assured by thorough training the data extractors. Authors picked $10 \%$ of the patient files randomly and extracted the same information extracted by the extractors to ensure the reliability and validity of the information. Authors re-entered $10 \%$ of the information entered by the data entry clerks to ensure that the data was correctly entered.

Garissa Level Five Hospital administration provided approval for data collection. Data collectors were trained and warned against abuse of the patient's information 
they came across in the files. Confidentiality of personal information in the files was maintained through coding.

\section{Statistical analysis}

Statistical Package for Social Science (SPSS) software version 17 was used to enter and analyse the data. Before analysis of data, frequency distributions were done to get the shape of distribution and presence of outliers to make decisions on which descriptive statistic to use. Descriptive statistics were used for continuous variables which had a normal distribution such as age, and the median was used for skewed data. Categorical data were presented as frequencies, while histograms were used to display frequency distributions.

\section{RESULTS}

A total of 330 women were included in the sample. Data recorded on marital status indicated that 85.2 percent of the women were married. The mean age of the women in years was 24.3 years [ $\pm 5.1 \mathrm{sd}]$, which ranged from 16 years to 40 years. About half $(52.5 \%)$ of the women were nulliparous and fairly young i.e., less than 20 years. Most of the women $(77.2 \%)$ had no previous history of caesarean section as shown in Figure 1.



Figure 1: Distribution of the history of previous caesarean section.

Indications for emergency caesarean section: Indications for caesarean section were a combination of maternal and foetal factors as shown in Figure 2. The main maternal indications for caesarean section were obstructed labour (18.5\%), prolonged labour (11.8\%) and previous scar $(10.8 \%)$. The foetal factors included foetal distress $(6.4 \%)$, non-reassuring foetal status $(6.1 \%)$ and malpresentation $(6.1 \%)$. Maternal/ foetal factors represented about $3 \%$ of the indications.

The decision to incision interval: These results are shown in Figure 3 indicate that though most of the mothers (74\%) gave consent within 30 minutes' guideline, only 3 percent of the mothers were prepared for the operation within that time. Only 24 percent of the caesarean sections were conducted within one hour after the decision was made for the operation.



Figure 2: Distribution of the indications for emergency caesarean section $(\%)$.



Figure 3: Distribution of the time span from decision to delivery of the baby.

Decision to incision interval and post-operative outcomes: The data shows that close to $2 / 3 \mathrm{rd}(62.4 \%)$ of the women had no complications after the caesarean section. Haemorrhage was the main complication which affected about $1 / 3^{\text {rd }}(32.4 \%)$ of the women. Only one out of the 330 women died from after the operation. The cause of the death was haemorrhage. The data indicates a tendency for bleeding to increase as the decision to incision interval increases from $1.8 \%$ the less than 30 
minutes interval to $9.4 \%$ in the 61 to 120 minutes. The details of these results are given in Figure 4.

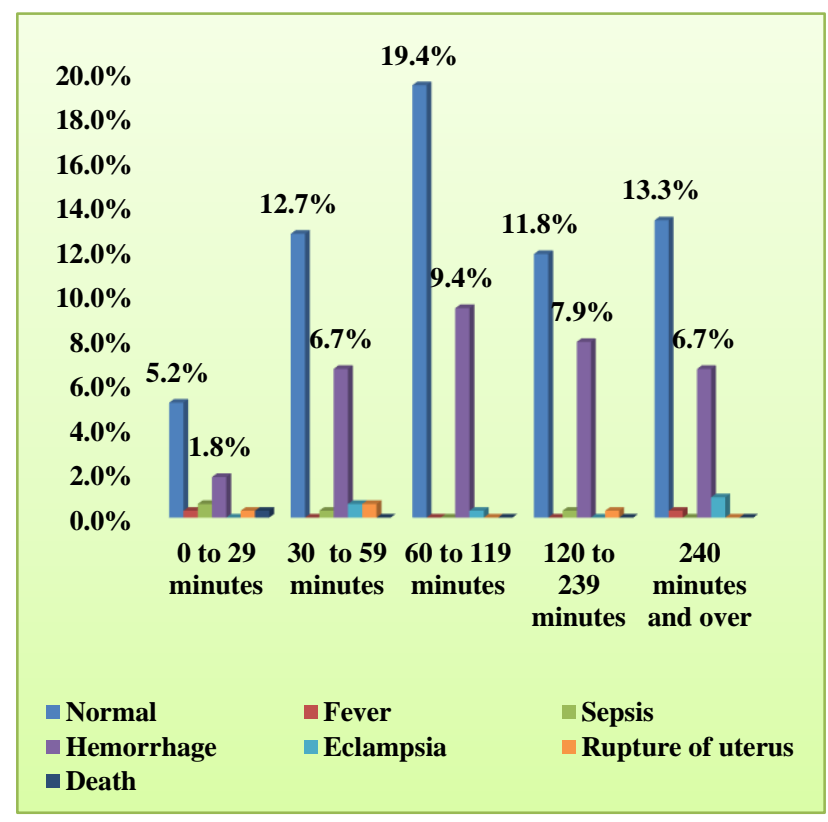

Figure 4: Distribution of decision-to incision interval and maternal post-operative outcomes.

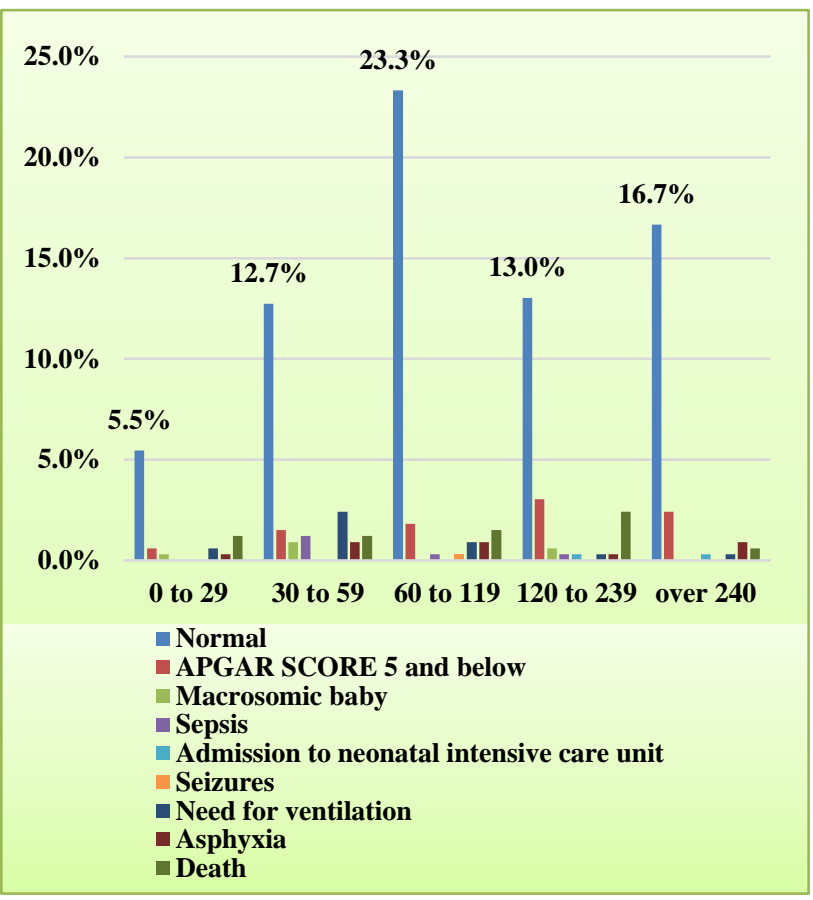

Figure 5: Decision-to incision interval and foetal postoperative outcomes.

Decision- to incision interval and foetal post-operative outcomes: The data given in Figure 5 shows that overall close to $3 / 4(71.2 \%)$ of the infants were born with no complications. Twenty-three $(7 \%)$ of the infants died. The main complication was babies with an Apgar score of 5 and below (9.4\% of the babies). The other complication was the need for ventilation which affected about $4.5 \%$. The total number of foetal deaths was 24 . The leading causes of foetal deaths were asphyxia and intra-uterine death.

\section{DISCUSSION}

The primary purpose of this study was to establish the extent to which the recommended 30- minute dictum of beginning a caesarean within 30 minutes of the decision to operate was achieved in a remote hospital with limited resources and its effect on the postoperative outcomes. The results indicate that mothers gave consent within the recommended time, but preparation by the health staff was the caused delays.

Thus, the delay in surgery was health facility and not patient related. The finding that women were able to consent promptly was contrary to the common perception that delays would be caused by the fact that women due to their cultural background and low education. Authors assumed that the consent would take longer since they had to consult before making decisions or may take time to be convinced. ${ }^{5}$

The explanation for the delays in preparing the mothers for surgery could have been related the hospital's incapability to respond to the obstetric emergency. The shortage of staff could have affected the transfer of the women to the theatre.

On average, the ratio of a labouring woman to midwife ratio is 6:1 during the day and can go up to 12:1 during the night in this hospital. This ratio is way over the recommended 1:1 necessary to achieve the 30-minute dictum. ${ }^{2}$ The hospital also had a shortage of professionals needed for the surgery- an anaesthetist, an obstetrician, a theatre nurse or midwife and a paediatrician.

At night, there are normally two nurses on duty in maternity, two interns on call, a medical officer is available on call and the obstetrician who can be accessed when needed. However, during the day all the staffs are available. Authors did not segregate daytime and night deliveries to show whether the DII differed at these times. In addition to staff shortages, only two out of the four theatres operate concurrently due to a shortage of staff, which could cause further delays.

Present findings show that only three percent of the caesarean deliveries commenced within 30 minutes of the decision to operate are in consonant with those found in other African countries including Kenya where the rates ranged from zero to six percent. ${ }^{8-13,16}$ This proportion is much lower than that found in developing countries of between 55 to 65 percent. ${ }^{2,7}$

Some authors have shown that emergency caesarean sections were associated with higher risks for maternal and infant morbidity while others give contrary results. Present findings show an association between DII and 
maternal and foetal post-operative complications agree with studies which demonstrated that for grade 1 and grade 2 caesareans, maternal and perinatal outcomes deteriorated when the decision-to-delivery interval exceeded 75 minutes. , $^{2,6,8,16-18}$

The main limitation of present study could have been the use of secondary data as there was no assurance of the quality and accuracy of recording. This study did not differentiate the grade 1 and two procedures to show how many of the women having a grade 1 caesarean delivered beyond the 30-minute benchmark when the life of the mother or foetus was in imminent danger.

It was not possible to state the precise clinical perception of urgency by the obstetrician in the caesarean deliveries performed. These results thus do not indicate how doctors prioritized the timing of caesarean delivery, or whether those incised within 30 minutes of the decision were those with an increased risk of compromise.

Authors did not look at the time spanning between the arrival of a woman in theatre and the delivery of the baby. The findings of present study which was a public hospital may not apply to private obstetric units or public hospitals in more developed counties of Kenya which might have better facilities.

\section{CONCLUSION}

Delays in preparing the mother for the caesarean section which resulted in not meeting the global standards were health facility-related and not patient related, thus the need to focus on the hospital infrastructural challenges. Evidence of adverse postoperative outcomes as a result of not meeting the standards remains inconclusive, and therefore there is a need for further studies especially those documenting the specific pre-operative and postoperative complications and the related post-operative caesarean section outcomes.

\section{ACKNOWLEDGMENTS}

Authors would like to thank the Great Lakes University of Kisumu for administrative support; Garissa Hospital for allowing to collect the secondary data from the patient's files and to data extractors.

\section{Funding: No funding sources}

Conflict of interest: None declared

Ethical approval: The study was approved by the GLUK Research Ethics Committee; Garissa Hospital permitted to collect the secondary data

\section{REFERENCES}

1. Bhutta ZA, Cabral S, Chan CW, Keenan WJ. Reducing maternal, newborn, and infant mortality globally: an integrated action agenda. Int J Gynecol Obstet. 2012 Oct;119(S1).
2. Cerbinskaite A, Malone S, McDermott J, Loughney AD. Emergency caesarean section: influences on the decision-to-delivery interval. J Preg. 2011;2011.

3. Tuffnell DJ, Wilkinson K, Beresford N. Interval between decision and delivery by caesarean section-are current standards achievable? Observational case series. Bmj. 2001 Jun 2;322(7298):1330-3.

4. Berek JS, Crum C, Friedlander M. Cancer of the ovary, fallopian tube, and peritoneum. Int J Gynecol Obstet 2012 Oct 1;119:S118-29.

5. Muula AS. Ethical and practical consideration of women choosing cesarean section deliveries without "medical indication" in developing countries. Croatian Med J. 2007 Feb;48(1):94.

6. Tolcher MC, Johnson RL, El-Nashar SA, West CP. Decision-to-incision time and neonatal outcomes: a systematic review and meta-analysis. Obstet Gynecol. 2014 Mar;123(3):536-48.

7. Bloom SL, Leveno KJ, Spong CY, Gilbert S, Hauth $\mathrm{JC}$, Landon MB, et al. Decision-to-incision times and maternal and infant outcomes. Obstet Gynecol. 2006 Jul;108(1):6-11.

8. Onah HE, Ibeziako N, Umezulike AC, Effetie ER, Ogbuokiri CM. Decision-delivery interval and perinatal outcome in emergency caesarean sections. J Obstet Gynaecol. 2005 May 1;25(4):342-6.

9. Shorunmu TO, Nathaniel GV, Oloyede OA, Adefuye PO, Ayodeji AB, Ukweduan IM, et al. The impact of decision-delivery interval on maternal and fetal outcome: a three-year experience in a tertiary hospital. Tropical J Obstet Gynaecol. 2015;32(1):4654.

10. Chukwudi OE, Okonkwo CA. Decision-delivery interval and perinatal outcome of emergency caesarean sections at a tertiary institution. Pak J Med Sci. 2014 Sep;30(5):946.

11. Rabiu KA, Adewunmi AA, Akinola OI, Eti AE, Tayo AO. Comparison of maternal and neonatal outcomes following caesarean section in second versus first stage of labour in a Tertiary Hospital in Nigeria. The Nigerian PG Med J. 2011 Sep;18(3):165-71.

12. Habib HA. Emergency caesarean section turnaround time and its effect on maternal and newborn health outcomes at University of Nairobi teaching hospitals (Doctoral dissertation, University of Nairobi). 2012:1-73.

13. Kagoni SE, Mwangi A, Chelagat D. Indication and outcomes of caesaerian section at moi teaching and referral hospital, eldoret, Kenya. Kenyan J Nurs Midwifery. 2017 Sep;2(2):114-23.

14. De Kamer. Annual Report 2012. 2012:1-37.

15. World Health Organization. Appropriate technology for birth. Lancet. 1985;2:436-7.

16. Gupta S, Naithani U, Madhanmohan C, Singh A, Reddy P, Gupta A. Evaluation of decision-todelivery interval in emergency cesarean section: A 1year prospective audit in a tertiary care hospital. $\mathrm{J}$ Anaesthesiol, Clinical Pharmacol. 2017 Jan;33(1):64. 
17. Rah JH, Akhter N, Semba RD, De Pee S, Bloem MW, Campbell AA, et al. Low dietary diversity is a predictor of child stunting in rural Bangladesh. Europ J Clinical Nutr. 2010 Dec;64(12):1393.

18. Singh R, Deo S, Pradeep Y. The decision-to-delivery interval in emergency Caesarean sections and its correlation with perinatal outcome: evidence from
204 deliveries in a developing country. Tropical Doc. 2012 Apr;42(2):67-9.

Cite this article as: Kamotho D, Pertet AM, Ogwayo I. Decision to incision interval for emergency caesarean section and postoperative outcomes in a resource limited rural Kenyan public hospital. Int J Reprod Contracept Obstet Gynecol 2018;7:2573-8. 